\title{
Study on the Development of Media and Its Education At the present stage
}

\author{
Xinyu Li \\ Henan University of Animal Husbandry and Economy \\ Zhengzhou,Henan,450046 China
}

\begin{abstract}
It is an important task to develop the media industry and liberate the media productive force. It is also inseparable from the productivity theory of Deng Xiaoping to recognize and analyze the problem, which is our ideological weapon. In the system, productivity theory is the core of its theoretical framework. Liberation of cultural productivity is a vital component of the Productivity Theory. In future, competition in the world will eventually become the competition of culture, and the liberation and development of cultural productivity has become one of the core topics in the 21st century. Media industry is the most important part in the cultural industry chain. It relates not only to the development of the media industry itself, but also to the development of cultural industries and the whole society and economy. The key to liberate the productive forces of media lies in the innovation of the system.
\end{abstract}

Keywords- Media Sciences; development; media education

\section{INTRODUCTION}

In the new era, science has developed rapidly. IVF, cloning technology or the nuclear power plant application have all proved that the rapid development of science and technology has become the norm. However, a series of problems brought up by the technological development happen now and then, catching more people's focus and attention. For example, paradox of eugenics and ethic, contradiction between nuclear technology and environmental pollution, in this context, the media' attitude will play a significant role not only to its development trends, but als o to people's idea and thoughts.

In the present-day society, the media has been able to expand to technology news. China's media can do accurate and objective report on time. However, through the patterns of science report, we can see that our news media coverage of science still cannot be comprehensive, objective, and news reporters still carry the black-or-white report thinking. News reporters lack mature operation mode and standard concepts when it comes to science news related to their interests. This is largely unfavorable to the development of science journalism.

\section{ST ATUS OF DIFFERENT T YPES OF MEDIA}

Chinese public's scientific literacy is relatively low, but it is also on the rise in recent years. It is reported that in 1996 in the third national survey of public scientific literacy, scientific literacy of people is only $0.3 \%$ of respondents, while the figure in 2001 investigation has been increased to $1.4 \%$. Although the data is still not satisfactory, the public's scientific literacy is accelerating its upward trend. According to the Xinhua News Agency in October 2001, in addition to formal education channels, there are $82.8 \%$ of the audience are through television, $52.1 \%$ of the audience are through the press. Chen Lidan also predicted in his On the Media misunderstanding of science that with rapid development of the network in the past two years, the proportion of scientific information from the network will sharply increase.

\section{A. Recognizing the liberation of the productive forces of the media and identifying the new ideas on the media industry from the fundamental task of socialism}

Comrade Deng Xiaoping pointed out that the fundamental task of socialism is to develop the productive forces. Only when the productive forces have developed can we meet people's increasing material and culture needs. Developing material productive forces alone is not enough to this end. In the late 1990s, the sudden emergence of metropolis newspaper in China has achieved economic and social benefits, which not only created enormous material wealth for the community, but also created a great spiritual wealth. Its success lies in a timely manner to meet the spiritual and cultural needs of the majority of urban residents. If we ignore people's cultural needs, the consequences will be unusually severe.

\section{B. Relying on the mass to liberate the media productive force}

We should rely on the mass to liberate the media productive forces, and assess productivity of China's media system depending on whether it is conducive to the development of the media. According to Comrade Xiaoping's productivity theory, people are the main advanced productive forces; they made history, created advanced culture and productivity. So in the big change of this media liberation, we should fully believe and rely on the masses so that they are able to play the leading role in this great transition. By making reform, we should mobilize the enthusiasm of the people involved in the liberation of the media productivity, improve the intensity of their participation and inspire them to create production potential. 
The way of doing everything alone is doomed to fail. In this transformation, we should pay particular attention to mobilize the enthusiasm of intellectuals to improve their sense of participation, providing them with a broad stage to display their talents. Intellectuals are an important part of the people, they are well-informed and have mastered the advanced knowledge, and therefore should play a vital role in the liberation of the media.

\section{China's media industry must be developed and improved}

On December 11, 2001, China formally joined the WTO, becoming the 143 me mber countries. Joining the WTO has affected the economic, political, cultural life in China and news media have also undergone new changes.

In such a background, China's media industry must be developed and improved, that is to say, China's media industry must make reform and transformation about the system, the demands value of the news media, media business models and other aspects. Liberation of media productivity not only related to the development of China's media industry, but also to the overall sustainable development of China's social and economic development, which is of huge meaning. Liberating media productivity, accelerating the development of the media industry are important parts of ourstrategy.

\section{Ppromoting the construction of the network media}

Development in decades has proved that to promote the healthy, order, sound and rapid development of the emerging Internet media, we must conscientiously adhere to the approach of "active use, scientific development, legal management, ensure the safety", firmly grasp the correct direction of the network media development; adhere to the direction of socialist advanced culture, occupy the network with scientific thinking and advanced culture ; insist to focus on construction, give full play to the important role of the Internet to promote economic development and social progress; insist on development and management, standardize the market order and protect civil rights to ensure network and information security and national interests; adhere to give priority to social efforts to make social and economic unity, and earnestly fulfill social responsibilities; insist on Chinese reality, as well as draw on the useful experience of various countries, and actively explore the Internet's development road with Chinese characteristics. Based on these valuable experience and practice, we should cherish and always adhere to improve and promote online media to make new progress.

Internet media should further enhance political awareness, sense of responsibility, sense of the overall situation. We should firmly grasp the correct guidance of public opinion and propaganda online, adhere to the theme, take the initiative, unequivocally publicize the socialist core value to promote the party's line, principles and policies and actively guide online hot topic, form high-spirited, energetic united mainstream. We must firmly establish the concept of the masses, make the online media guide as affective way to contact with the masses and study on the characteristics and laws of online public opinion, adhere closely to reality, life, and the masses, unite the ideology and guide better, unify the accessibility of public sentiment and creation of a civilized and rational expression of the environment, focus on correct fact-orientation, form common sense while interacting with the public, strengthen information services to carry out ideological education, speak on the facts, resolve conflicts, manage emotions, and constantly enhance the online public opinion to guide the work of affinity.

\section{MEDIA GUIDE}

\section{A. Correct guidance of public opinion}

Public opinion is the mix of strong and lasting common views, attitudes and beliefs. Mass media coverage of the event will directly affect people's awareness of the event, the amount of coverage for the event can cause people to respond differently to this event. If the mass media report something repeatedly, people will begin to pay attention to this matter, and therefore the public opinion will naturally be formed. Mass media not only arouse public opinion, but also form a correct opinion. Correct opinion is to meet the national interests and the interests of the majority of the people. In the process of building a socialist harmonious society, one of the important social responsibilities of the mass media is to guide public opinion on the track to the interests of the society and people.

\section{B. Accurate information communications}

Mass media is the intermediary of information flow in the information society, information exposure are mostly dependent on the mass media. Communication of information allows people to understand the changes in the surrounding circumstances, to adjust themselves to better adapt to changes in the environment. Harmonious socialist society will not continue without maintenance of good relationships, relatives, friends, colleagues, neighbors and other interpersonal communication. It depends on smooth and accurate information. Mass Media has technical advantages that can provide accurate information to the people about surrounding environment changes timely. Mass media is seen as the power except government administrative powers. Transparency and accurate flow of information can make the government's actions more efficient, incorruptible, and avoid the serious damage caused by secret operations.

On the one hand, all kinds of information are in need of spreading way; on the other hand, campus mainstream media ignore the management. The two factors caused the chaos in campus media area. Many of the information are useful, but there also includes a lot of bad content. These all call for a new identification for campus media and improvement of self-management.

In short, the tide of the media industry has been surging in the new century in China. Under this environment, the existing rules and concepts are constantly deconstructed; the law of "survival of the fittest" has shown its strong selection effect in media filed. Schools cannot exist independently from society, so as the campus media industry, campus media is an important part of our media industry. In this 
industrialization world today, its industrial properties are constantly germinating. Diverse campus media management will become the future trend of development of the media.

\section{DEVELOPMENT OF MEDIA EDUCATION}

A variety of social media began to penetrate the university campus in many ways; especially the popularity of the Internet has opened up a vast space to the students. In this situation, the impact of campus media will become increasingly weak. Within the university community, a variety of nonofficial media is popular, including various formal community newspapers, such as various forms of flyers, DM, besides, there are still a variety of negative publications.

\section{CORE ESSENCE OF MEDIA EDUCATION}

Media literacy is a relatively new term in China. It closely related to the social and cultural development. According to American Media Research Center, Media Literacy refers to the ability to select, understand, question, assess, create and produce the information when faced a lot of news. Thus, the subject of media literacy is the audience; the investigated object is the attitude of the audience's information capabilities, and the use of cognitive level. Media literacy is extended ability of traditional literacy, which includes people's ability to interpret the information in all forms, except the ability of listening, speaking, reading and writing, there are other abilities such as critically watch, listen and interpret television, radio, Internet, newspapers, magazines, advertising and so on. Of course it also includes the ability to use information technology to produce a wide variety of media information.

\section{ANALYSIS ON THE CAUSES OF MEDIA EDUCATION DEVELOPMENT PROBLEMS}

For a nascent discipline in our country, the media education is still unfamiliar to most people, because of the lack of practice among the public, as well as the immature theory system. Although China's media literacy education is in the development period, the pace is slow compared with that of the foreign. Overall, at present, China's media literacy education is still in its infancy period whose main features are listed below:

\section{A. Unformed Media Education theory system suitable for China}

Although Chinese people have realized the importance of media literacy education, because of the infancy period, there is no in-depth study of the theory, it is just the introduction of foreign theory, and the research has not yet achieved a qualitative leap. Some scholars pointed out theory suitable for China's theoretical situation, but there is little theory which is actual related to real situation of Chinese citizen's media literacy and the national conditions.

\section{B. Guidepractice relying on journalism, communication, education, and other related media education theory}

In the development process, disseminate research, education, psychology and other fields of cultural studies have become a source of media education theory, directly affecting the practice of media education. Such as the Marxist concept in journalism is the fundamental requirements to propaganda. Besides, it is learned that distinct political consciousness and orientation is an important feature of the news media. It is also a propaganda tool for the ruling party to create a good atmosphere for socialist construction, and a guarantee to achieve development goals. Media education must clarify this point, especially when learn from Western media philosophy. Media must have a clear sense of party spirit, and avoid mechanically copy or imitate.

\section{REFERENCES}

[1] Hu Zhifeng. Under the new situation of scientific research on how the media to promote media education development [J]. Modern communication (Communication University of China),2011,07:16-18.

[2] Yang Lin. Of Media Ecology and media industry to build the scientific development concept [J]. Lanzhou University (Social Science Edition),2007,01:71-75.

[3] Huangjiamo. Establish and implement the scientific concept of development and the role of the media [J]. News window,2007,04:4 6.

[4] Wangyang. Improve the ability to achieve scientific development to guide public opinion media [J]. Media,2012,12:34-35.

[5] Lanbotao. College Students Marxist concept of national education research [D]. Southwest University, 2011.

[6] Liuyuhua. Mass Media and Rural Development virtuous circle of decision theory to explore [D]. Jilin University, 2004.

[7] Caoyan Ning. employment-oriented public research university students under the Scientific Development Concept - the moment the media's interpretation of ideological and political education [J] press, 2009,05:75-76 +142. 